\title{
WINNING THE WAR AGAINST COVID-19 IN MALAYSIA: AN ACHIEVABLE GOAL?
}

\author{
Hafiz Jaafar ${ }^{1}$ and Amirah Azzeri ${ }^{2}$ \\ ${ }^{1}$ Department of Primary Care, Faculty of Medicine and Health Sciences, Universiti Sains Islam Malaysia \\ ${ }^{2}$ Department of Research, Development and Innovation, Universiti Malaya Medical Centre
}

Corresponding author: Mohd Hafiz Bin Jaafar

Email: drhafizjaafar@gmail.com

Novel coronavirus infection (COVID-19) was first detected on December 31, 2019, in Wuhan, China ${ }^{1}$ and has spread to many countries across the globe. To date, about 2,959,929 confirmed cases and 202,733 deaths were reported worldwide ${ }^{2}$. The World Health Organization (WHO) has initially categorised COVID-19 infection as a Public Health Emergency of International Concern (PHEIC) in late January $2020^{3}$ and later on declared the outbreak as a pandemic on March 11, 2020, due to the rapid increased in the number of positive cases in a short period of time ${ }^{4}$.

On February 4, 2020, the first Malaysian positive COVID-19 patient was detected and subsequently resulted in 22 positive cases until February 15, $2020^{5}$. The second wave of the outbreak started in early March following a mass gathering of a religious event in Kuala Lumpur, which was held on February 27 to March 1, 2020. The event has resulted in an exponential increased in the number of positive cases and contributes to the biggest cluster of Covid-19 in Malaysia. To date, Malaysia has 6,535 cumulative positive cases with almost $50 \%$ of them were related to the event. The first two deaths due to COVID-19 in Malaysia were reported on March 16, 2020, and one of the deceases was the religious event attendee ${ }^{6}$. The infection chain triggered by the event has already widened and has gone into the fifth generation.

The Government of Malaysia has decided to implement a Movement Control Order (MCO) started on March 18, 20207. Nevertheless, the announcement on the implementation of the MCO has triggered panic-buying of essential items and massive crowds of people at bus and train stations purchasing tickets to go back to their hometown, which interfered social distancing and defeated the main purpose of the MCO; to limit the spread of the infection. This could result in a new surge of infection. It was reported that in the first two days of the MCO, only $60 \%$ of Malaysians obeyed the order, which forced the government to deploy, and mobilised armies to assist the enforcement ${ }^{8}$.

Malaysia could have another spike of Covid-19 infection, the third wave that could probably due to the uncooperative patients who did not disclose their travel histories and flouting quarantine conditions, which put a higher risk of infection to the front liners and healthcare workers. The third wave could also be caused by the number of Malaysian's students and workers returning from overseas and also among people who had travelled before the lockdown came into force on March 18.

Assuming that no preventive measures such as MCO and compulsory 14 days quarantine for travellers who came back from overseas took place, it was estimated through a thorough decision tree technique that cumulatively 22,000 positive patients were expected to be infected nationwide. At the current rate of disease detection, screening yield and clinical capacity in Malaysia, the identification of the positive patients will have to be continuously done until the middle of May 2020 with cumulative tests conducted, cumulative positive cases, the cumulative number of patients in care, cumulative admission to intensive care unit, the cumulative requirement for ventilators, cumulative death and cumulative discharge estimated at 327,697, 22,742, 16,684, 667, 317, 373 and 5,686 respectively.

Recently, WHO has recommended countries to scaled-up screening initiatives since many individuals living with COVID-19 are asymptomatic'. Malaysia is now planning to conduct massive case detection by increasing the testing capacity to 16,500 tests daily as announced in early March ${ }^{6}$. A prediction with the forecasted testing capacity was made through decision tree technique with several parameters included. In contrast with the earlier estimation, massive testing causes the number of positive patients to be saturated earlier, by the end of April 2020. Based on the projection, 346,307 cumulative tests will be conducted with 22,510 cumulative positive cases will be identified. Of the numbers, the cumulative number of patients in care would be 17,631 with 705 cumulative number of admission to the intensive care unit and 353 cumulative patients required for ventilators. The cumulative death and cumulative discharge are expected to be 394 and 6,008 respectively. 
Currently, increasing the number of tests without the optimum capacity to handle the volume at laboratories might not be helpful because there will be long waits for people to find out whether they are positive or not. With the current laboratory and resources capacity, it is challenging for Malaysia to curb the epidemic due to the constraints of healthcare resources. The screening and laboratory capacities in Malaysia are still low compared to other developed countries, which causes the government to priorities testing strategies among highly suspected patients ${ }^{10}$. These challenges potentially highlight the need for realistic strategies concerning the country's capacity. It would be useful to have a point of care testing with a short turnaround time to ensure timely diagnosis and initiation of treatment can be made. Presently, Malaysia could increase the capacity of processing the test through public and private sectors engagement at private hospitals and private medical and allied science universities that can run the tests.

In conclusion, the successful optimization of healthcare resources particularly the COVID-19 testing relies on the appropriate decision-making and healthcare management. Public and private hospitals and universities engagement could help to manage supplies effectively especially when a critical shortage of resources is projected.

\section{REFERENCES}

1. Jiaye $L$, Xuejiao $L$, Shen $Q$, et al. Community transmission of severe acute respiratory syndrome coronavirus 2, Shenzhen, China. Emerg Infect Dis. 2020;26(6).

2. World Health Organisation. Novel Coronavirus (COVID-19) Situation. 2020.

https://who.maps.arcgis.com/apps/ opsdashboard/index.html\#/c88e37cf c43b4ed3baf977d77e4a0667.

Accessed March 27, 2020.

3. WHO. 2019 novel coronavirus (2019$\mathrm{nCoV})$ : Strategic preparedness and response plan. 2020. https://www.who.int/docs/defaultsource/coronaviruse/srp04022020.pdfExternal Link. Accessed March 27, 1BC.

4. Cable News Network. Coronavirus
Outbreak Timeline Fast Facts. 2020. https: / / krdo.com/health/2020/03/2 4/wuhan-coronavirus-timeline-fastfacts/. Accessed March 27, 2020.

5. Garda World. Malaysia: First Cases of 2019-nCoV Confirmed January 25. 2020.

https://www.garda.com/crisis24/ne ws-alerts/308496/malaysia-firstcases-of-2019-ncov-confirmedjanuary-25. Accessed March 27, 2020.

6. Abdullah H. Updates On The Coronavirus Disease 2019 (COVID-19): Situation In Malaysia. Ministry of Health Malaysia. 2020.

7. Astro Awani. MCO extended until April 14th: Don't panic, PM tells Malaysians. 2020. https: / / beta.astroawani.com/videomalaysia/mco-extended-until-april14th-don-t-panic-pm-tells-m-sianskini-news-25-mar-1840036. Accessed March 27, 2020.

8. Choong J. Only $60 \%$ complied with MCO: Police may take sterner action. Malay Mail Online. 2020. https: / /www.malaymail.com/news/ malaysia/2020/03/19/ismail-sabrifour-in-10-malaysians-violatingmovement-control-order/1848077. Accessed April 29, 1BC.

9. World Health Organization. WHO Director-General's Opening remarks at the media briefing on COVID-19. 2020.

https://www.who.int/dg/speeches/ detail/who-director-general-sopening-remarks-at-the-mediabriefing-on-covid-19---16-march2020. Accessed March 27, 1BC.

10. Max R, Hannah R, Esteban 0-O. Coronavirus Disease (COVID-19) Statistics and research. 2020. https: / / ourworldindata.org/coronavi rus. Accessed March 27, 2020. 